\title{
Characterization of Five Different South African Waste Foundry Sands to Determine their Suitability for Use in Concrete
}

\author{
Patrick I. Iloh, Prof. George Fanourakis, Aurobindo Ogra
}

\begin{abstract}
South Africa, like many other countries is witnessing the fast growth of the construction industry. Concrete is one of the key materials used for the development of infrastructures. Sand as one of the natural resources and major concrete components is depleting universally. At the same time, the solid waste generated from industries is gaining momentum and increasing drastically. Researchers have indicated that Waste Foundry Sand (WFS) has the potential properties for use as fine aggregate in concrete. The full/partial replacement of sand in concrete with WFS not only makes concrete manufacturing economical, but also helps in reducing disposal problems and promote sustainable construction. In this study, the physical and chemical properties of five WFS's from Gauteng, South Africa were analysed (two green and three chemically bonded moulding sands). The samples were investigated with a view to determine their conformity with applicable engineering standards when used as fine aggregate. The physical and chemical properties evaluated were particle gradation, specific gravity, moisture content, clay contents, bulk density, $\mathrm{XRF}$ and $\mathrm{pH}$. The physical and chemical results of the five WFS's analysed indicate acceptable variations in chemically bonded moulding sand. The green sands proved unacceptable for use as fine aggregate for concrete use due to their: clay contents, poor grading which cannot be blended with other sand, and due to the presence of fine and silt particles which can cause bleeding and segregation.
\end{abstract}

Keywordss - Chemical properties, Gradation, Physical properties, Waste Foundry Sand (WFS).

\section{INTRODUCTION}

In this 21st Century, concrete has become the largest utilized synthetic construction material product on earth. Globally, concrete production in the year 2010 was estimated to be 16 billion tons [1]. Based on an approximate world population of 7 billion, this translates into more than two tons of concrete produced per person per year, which brings into spotlight the scale of concrete usage. Concrete is a mixture of

Manuscript received October 17, 2017. This work has been supported by the University of Johannesburg and five foundries in Gauteng.

Patrick I. Iloh, Research Masters Student, Department of Civil Engineering Technology, Faculty of Engineering and the Built Environment, University of Johannesburg, South Africa (e-mail: ipatrickiloh@gmail.com)

Prof. George Fanourakis, Department of Civil Engineering Technology, Faculty of Engineering and the Built Environment, University of Johannesburg, South Africa (e-mail: georgef@uj.ac.za)

Aurobindo Ogra, Department of Town and Regional Planning, Faculty of Engineering and the Built Environment, University of Johannesburg, South Africa (e-mail: aogra@uj.ac.za). cement (10\% - $11 \%)$, Aggregate (70\% - $85 \%)$, Water (13\% - $20 \%$ ) [2]. Natural sand (river sand) is one of the main ingredients used as a fine aggregate in concrete production. Because of these immense amounts of natural sand needed, the industry has left a large negatively impacting environmental track, which is a sturdy challenge to overcome.

A growing demand for construction material has led to the over-exploitation by legal and illegal mining and this has led to damaging costs e.g. an increase in riverbed depths and lowering of the water table [3]. In South Africa, a large amount of natural sand has been extracted. The sand utilization in 2015 was $1900 \mathrm{Mt}$ and trends suggest an $8 \%$ annual increase in sand usage. To abate the use of natural sand in concrete, the South Africa Waste Management Act 2008 [4] provides an incentive that encourages the use of waste materials as an alternative material. Substituting the natural sand with WFS, where practicable, allows for present levels of sand demand to be met, whilst conserving the prime aggregates and accordingly reducing deposits on landfills. According to previous studies, WFS grain size distribution is uniform, with $85 \%-95 \%$ of the material between the $0.6 \mathrm{~mm}$ to $0.150 \mathrm{~mm}$ size range, and approximately $5 \%$ to $20 \%$ of WFS can be finer than $0.075 \mathrm{~mm}$ [5]. According to Dayton et.al. (2010), spent foundry sand prevailing size portion ranges from 0.05 to $2 \mathrm{~mm}$, which extends from $76.6 \%$ to $100 \%$, with a median of $90.3 \%$ on the research done on 39 spent foundry sands. The specific gravity of WFS differs between 2.39 and 2.79. WFS has a low water absorption limit and is non-plastic [6]. Other researchers have suggested that the workability and suitability of WFS in flowable fill depends upon its physical properties such as particle gradation, fine contents, density, and absorption and specific gravity [7]. Whereas others have reported that variation in the bulk density $(1052-1554 \mathrm{~kg} / \mathrm{m} 3)$, specific gravity (2.38-2.72) and absorption (0.38-4.15\%) largely depends on the sand mineralogy, particle gradation, grain shapes and fine contents [8]. WFS been rich in silica content, few researchers have reported that its chemical composition relies on the type of binder, type of metal and combustible utilised [9]-[10]. It is coated with a thin film of burnt carbon, residual binder (bentonite, sea coal, and resins/chemicals) and dust. Its $\mathrm{pH}$ has been reported as varying between 4 and 8 , depending on the type of binder and type of metal cast [11]. Previous research reported that due to the presence of phenols in foundry sand, some waste sand could be corrosive to metal. This raised concerns that infiltration of 
precipitation over build up stocks could assemble leachable segments, resulting in the discharge of phenol into ground water supplies or surface water supplies [12].

For this reason, the WFS physical properties and chemical composition must be well understood. An International survey [13] found that particle size and grading, strength, water requirement, absorption and specific gravity are amongst the most significant material characteristics for concrete quality. Hence, the effect of the inclusion of WFS on the above properties of concrete warrants investigation.

In this research study, the suitability of two commonly used South African WFS's namely the greensand (clay bonded) and the chemically bonded moulding sand for use in concrete was ascertained.

\section{II.TESTING PROGRAM}

\section{A. Materials}

Five WFSs were collected from five different independent metal casting foundries with different casting processes from Gauteng Province, South Africa. Two greensands were collected from Auto Industrial (Isando Foundry) and Guestro Casting and Machining, representing samples (WFS 01 and WFS 03), and three chemically bonded moulding sands from Forbes Bros. Foundry, Johannesburg Foundry rebranded as Sinvac Casting, and Thomas Foundry representing samples (WFS 02, WFS 04, and WFS 05) respectively. Each sample of $10 \mathrm{~kg}$ disposable WFS to landfill site was collected from the respective foundries. All the samples were decanted into clean buckets and were transported for subsequence investigation to the laboratory. The methods used to determine the physical and chemical properties of the material are discussed below.

\section{B. Methods}

Physical Properties:

Sieve analysis (Grading): This is the process of dividing an aggregates sample into certain segments, each comprising of particles of similar size [14]. Sieving can be done in different ways; SANS 201 [15] describes the method for dry sieving of aggregates, which was used as the method for determining the particle size distribution curve (PSD) of the five WFS in this study. Gradation, especially grading of the WFS, is an important factor in concrete production as it influences the concrete properties in fresh state.

Hydrometer analysis: The TMH1-Method A6 [16] test method was used to determine the distribution of the five WFS particle size smaller than $0.075 \mathrm{~mm}$, by means of the sedimentation process, based on Stokes's law.

Relative density (SG): Specific gravity of solid soil is the proportion of the mass of a unit volume of a solids soil to the mass of the same volume of gas free distilled water at $20^{\circ} \mathrm{C}$. Determination of relative density was conducted in accordance with SANS 3001-AG23:2014 [17] for solids soil that pass through $4.75 \mathrm{~mm}$ sieve by pycnometer method.

Moisture content: Determination of the moisture content by oven drying of the five WFSs used in this study conform to SANS 3001-GR20 [18]. The moisture form of WFS is significant as it affects the overall water content of the mix, in turn, affecting strength and workability.

Uncompacted bulk density: A standard method, which conforms to SANS 5845:2006 [19], was used to determine the uncompacted bulk densities of the five WFS samples. Reasonably, the density of aggregate affects the concrete aggregate proportioning.

Fineness Modulus (FM): FM is a dimensionless limit, which defines the average particle size [20] and give a suggestion of the fineness or coarseness of the aggregate [21]. The Fineness Modulus of the five WFS samples used in this study was determined by sieving the material on the specified sieves and calculated by adding the cumulative percentage passing the $4.75 \mathrm{~mm}, 2.36 \mathrm{~mm}, 1.18 \mathrm{~mm}, 0.6 \mathrm{~mm}, 0.3 \mathrm{~mm}$ and $0.15 \mathrm{~mm}$, and divided by 100 . This method was carried out in accordance with SANS 201 [15].

Chemical properties :

$\boldsymbol{X R F}$ : The five WFS samples were analysed using a Rigaku ZSX Primus II X-ray spectrometer. An approximate $10 \mathrm{~g}$ sample of each non-grounded dry sample was pressed to form a pellet after mixing with wax. It was then placed into the sample holder of the XRF spectrometer for quantitative analysis of the chemical composition.

$\boldsymbol{p H}$ : The acidity or basicity of the five WFS was measured using as aqueous solution. Solutions with a $\mathrm{pH}$ fewer than 7 are said to be acidic and solutions with a $\mathrm{pH}$ more than 7 are basic or alkaline. The $\mathrm{pH}$ was determined in accordance with (SANS 11:1990) [22].

\section{RESULTS AND DISCUSSION}

\section{A. Physical Properties of WFS}

Grading: The grain size distribution of WFS is relatively uniform, with a mainstream of the sizes falling within a narrow range between the $0.600 \mathrm{~mm}$ and $0.150 \mathrm{~mm}$ sieves. The majority of the WFS materials reported are found to be medium to fine sand. WFS have been found to be too fine to satisfy the specifications for general fine aggregate [23]. This includes the effective size, coefficient of curvature, and coefficient of uniformity of WFS samples. According to Unified Soil Classification System ASTM D2487-06 [24], coefficient of curvature, $\mathrm{C}_{\mathrm{c}}$, ranges from 1.5 to 2.5 ; coefficient of uniformity, $\mathrm{C}_{\mathrm{u}}$, ranges from 0.9 to 1.5 . The gradation results are consistence with previous research [25]-[26]. Figure 1 summarizes the test results of five WFS samples gradation curves. The sieve analysis data of five WFS sample are presented in Table 1, along with the SANS 1083: 2017 [27] standard grading requirements for fine aggregate used in concrete mixes. Each value was achieved from a sample test. WFS samples from the chemically bonded moulding sand (WFS 02), and greensand (WFS 01), had respective grain sizes of 12 and $21 \%$ passing through the $0.150 \mathrm{~mm}$ sieve, satisfying the grading limit criteria. Similarly, $42 \%$ and 53\% of WFS 03 and WFS 05 were poorly graded and, as a result, cannot be blended with other fine aggregate for concrete, as they did not meet the grading limit of $0.150 \mathrm{~mm}$. The WFS 04, which had 4 $\%$ passing the $0.150 \mathrm{~mm}$ sieve, complies with Alexander and Mindess, 2005 suggestion of a lower limit of 3\% passing the 
$0.150 \mathrm{~mm}[28]$. These plots variations show that WFS's are less graded and finer than fine aggregate for concrete, with the majority of the sizes falling within SANS 1083:2017 [27] range of $0.150 \mathrm{~mm}$ sieves with grading limit of $5 \%$ and $25 \%$.

From the grading curve presented in Table 2, the uniformity coefficient and the coefficients of gradation of $\mathrm{D}_{10}, \mathrm{D}_{30}$, and $\mathrm{D}_{60}$ diameters corresponding to $10 \%, 30 \%$ and $60 \%$ finer in the particle-distribution of WFS 01-WFS 05 for $\mathrm{C}_{\mathrm{u}}$ is 5.25 , 2.00, 7.87, 2.33, and 2.25, while for $\mathrm{C}_{\mathrm{c}}$ is $2.03,0.89,1.61$, 1.20 , and 0.84 .

Fines content results are shown in Table 3, i.e., particles proportions of five WFS finer than $75 \mu \mathrm{m}$ by dry sieving. The results ranged between $16.77 \mathrm{~g}(13 \%), 3.51 \mathrm{~g}(2.8 \%), 31.77 \mathrm{~g}$ (25\%), 2.2g (1.76\%), and 5.52g (4\%), respectively and were on average $9.3 \%$, consistent with previous report results [28]. The clay bonded WFS samples, WFS 01 and WFS 03 contained comparatively more fines (on average 19\%) than chemically bonded WFS samples (on average $2.9 \%$ ). For the clay bonded WFS, it is contingent that clay bonded WFS occupied the most of fine contents. Apart from the clay contents, fines are also comprised of very fine sand particles and silt which are dispersed by the wash water, the residue chemical additives and binders from the casting process.

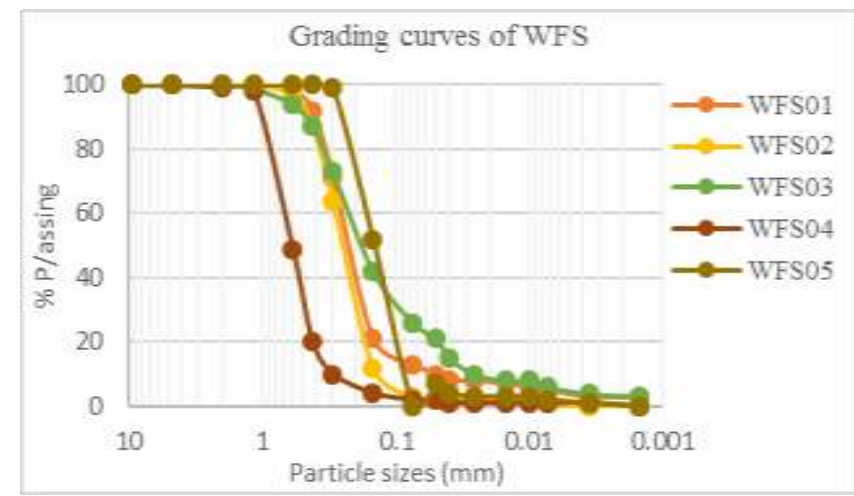

Fig. 1 Gradation curves of sieve and hydrometer analysis of WFS

TABLE 1: PARTICLE SIZE DISTRIBUTION (SIEVE ANALYSIS AND HYDROMETER ANALYSIS) RESULTS

\begin{tabular}{lcccccc}
\hline Total Mass & \multicolumn{5}{c}{ * Sample: 125 grams } \\
\hline $\begin{array}{l}\text { Sieve Size } \\
(\mathrm{mm})\end{array}$ & WFS01 & WFS02 & WFS03 & WFS04 & WFS05 & $\begin{array}{l}\text { Grading } \\
\text { Limit }^{1}\end{array}$ \\
4.750 & 100 & 100 & 100 & 100 & 100 & 90 - 100 \\
2.000 & 100 & 100 & 100 & 99 & 100 & - \\
1.180 & 100 & 100 & 99 & 98 & 100 & - \\
0.600 & 98 & 97 & 94 & 49 & 100 & - \\
0.425 & 92 & 87 & 87 & 20 & 100 & - \\
0.300 & 71 & 64 & 73 & 10 & 99 & - \\
0.150 & 21 & 12 & 42 & 4 & 52 & $5-25$ \\
0.075 & 13 & 3 & 26 & 2 & 11 & \\
0.050 & 10 & 2 & 21 & 2 & 7 & \\
0.040 & 8 & 2 & 15 & 1 & 4 & \\
0.026 & 8 & 2 & 10 & 1 & 3 & \\
0.015 & 7 & 2 & 8 & 1 & 3 & \\
0.010 & 6 & 2 & 8 & 1 & 3 & \\
0.0074 & 5 & 1 & 6 & 1 & 2 & \\
0.0036 & 4 & 0 & 4 & 1 & 1 & \\
0.0015 & 3 & 0 & 3 & 0 & 0 & \\
\hline \hline
\end{tabular}

*WFS01-05 (\% passing); 1SANS 1083: 2017
TABLE 2: WFS EFFECTIVE SIZE, UNIFORMITY COEFFICIENT, AND COEFFICIENT GRADATION SUMMARY RESULTS

\begin{tabular}{cccccc}
\hline \hline Samples & WFS 01 & WFS 02 & WFS 03 & WFS 04 & WFS 05 \\
\hline \hline $\mathrm{D}_{10}$ & 0.055 & 0.15 & 0.028 & 0.3 & 0.08 \\
$\mathrm{D}_{30}$ & 0.18 & 0.20 & 0.10 & 0.5 & 0.11 \\
$\mathrm{D}_{60}$ & 0.29 & 0.30 & 0.22 & 0.7 & 0.18 \\
$\mathrm{C}_{\mathrm{c}}$ & 2.03 & 0.89 & 1.61 & 1.20 & 0.84 \\
$\mathrm{C}_{\mathrm{u}}$ & 5.27 & 2.00 & 7.87 & 2.33 & 2.25 \\
\hline \hline
\end{tabular}

Relative density (SG). The specific gravity of WFS rests on the internal porosity of the constituent particles as well as chemical composition of the sand. Sands with high metal contents will have higher specific gravities. The specific gravities reported in the previous works on four green sand samples ranged from 1.985 to $2.45[10,29]$. The specific gravity of a chemically bonded WFS was found to be 2.60 [29]. The variation in the specific gravity as shown in Table 3 from the five WFS samples (WFS 01-WFS 05) ranged between $(2.3-2.8)$. This dissimilarity may be attributed to the variation in particle gradation, sand mineralogy, fine content, grain shape, and sand binder. The sea coal dust, which is known to be porous with carbon content, might have resulted in lower specific gravity for the green WFS.

Moisture contents of the WFS test results represent the "Equilibrium Moisture" state of individual sample; that is, the sample will neither absorb water nor give up water to the paste. In previous research, WFS's have been reported to be virtually dry. Though, variation from one foundry to another, and the method in which the WFS's are stockpiled may result in the moisture contents inconsistency. The moisture content for greensand samples has been reported to be in the range of $0.08 \%$ to $4.59 \%$, and chemically bonded samples was reported to be in the range of $0.11 \%$ to $3.48 \%$ [10]. The moisture content of the five WFS analysed ranged from $0.2 \%$ to $8.3 \%$, as presented in Table 3 . The chemically bonded sample, WFS 02 , exhibited a very high water content of $8.3 \%$, while sample WFS 03 had a moisture content of $1.9 \%$. Samples WFS 01, WFS 04 and WFS 05 had moisture contents less than $1 \%$. The varied initial water content set in the foundry sands and binder type may be related to these differences. Green sand (claybonded) system require approximately $10 \%$ of water to activate (bentonite binding), however $2 \%-3 \%$ water is required as a catalyst or solvent for organic binders' activation [30]. Neglecting moisture content can incorrectly affect the calculation of volume of water in mix design.

Uncompacted bulk density. The results of the five sands, which are included in Table 3 , ranged from $1165 \mathrm{~kg} / \mathrm{m}^{3}$ to $1473 \mathrm{~kg} / \mathrm{m}^{3}$ ). This capacity possibly will be ascribed to the variation in particle gradation, sand mineralogy, fine content, and grain shape. According to SANS 5845:2006 [19] The uncompacted bulk density should exceed 1120 (for lightweight concrete). Hence, all the sands complied with this criterium.

Fineness Modulus (FM) of the five samples are shown in Table 3. According to SANS 1083: 2017 [26], the limiting FM for fine aggregate for concrete use range from 1.2 to 3.5. Samples WFS 01, WFS 02 and WFS 04 complied with standard FM's of 1.2 1.4, and 3.2, respectively. Samples WFS 03 and WFS 05 had FM's of 1.0 and 0.5 , respectively. 
TABLE 3: PHYSICAL PROPERTIES OF WFS SAMPLE

\begin{tabular}{cccccccc}
\hline \hline Samples & $\begin{array}{c}\text { Most. } \\
\text { Content } \\
(\%)\end{array}$ & $\begin{array}{l}\text { Bulk } \\
\text { Density } \\
(\mathrm{B})\end{array}$ & $\begin{array}{c}\text { SG } \\
(\mathrm{C})\end{array}$ & $\begin{array}{c}\text { FM } \\
\text { (D) }\end{array}$ & $\begin{array}{c}\text { Clay } \\
\text { Content } \\
(2,0 \%) \\
(\mathrm{E})\end{array}$ & $p H$ & $\begin{array}{c}\text { WFS } \\
\text { finer } \\
\text { than } \\
75 \mu \mathrm{m}\end{array}$ \\
\hline \hline WFS 01 & 0.4 & 1247 & 2.5 & 1.2 & 3,0 & 8.88 & 13 \\
WFS 02 & 8.3 & 1387 & 2.6 & 1.4 & 0,0 & 9.34 & 3 \\
WFS 03 & 1.9 & 1165 & 2.3 & 1.0 & 3,0 & 8.87 & 26 \\
WFS 04 & 0.5 & 1221 & 2.6 & 3.2 & 0,0 & 9.89 & 2 \\
WFS 05 & 0.2 & 1437 & 2.8 & 0.5 & 0,0 & 9.52 & 4 \\
\hline \hline
\end{tabular}

(A) SANS 3001-GR20; (B) SANS 5845:2006 $\mathrm{Kg} / \mathrm{m}^{3}$; (C) SANS 3001AG23:2014; (D) SANS 1083:2017(1,2 - 3,5); (E) SANS 1083;2017; (F) SANS 11:1990 Alkaline; (G) SANS 1083:2017

\section{B. Chemical Properties of WFS}

$X$-ray fluorescence $(X R F)$ : From the results, which are shown in Table 4, the predominant element existing in all samples is silica oxide with highest percentage present. When comparing the elemental composition of clay bonded WFS samples (WFS 01 and WFS 03) to chemically bonded samples (WFS 02, WFS 04 and WFS 05), it was observed that the latter comprised fewer $\mathrm{Al}_{2} \mathrm{O}_{3}$, and had no trace of $\mathrm{MgO}$; this can be ascribed to partial loss of binder and high casting temperature. The main components were found to be silica $\left(\mathrm{SiO}_{2}\right)$, alumina $\left(\mathrm{Al}_{2} \mathrm{O}_{3}\right)$, and ferric oxide $\left(\mathrm{Fe}_{2} \mathrm{O}_{3}\right)$.

The composition was found to be very suitable for the manufacturing of Portland cements.

$p H$ : These results are very important in the evaluation of sand compatibility with applied resins. The clay bonded (WFS01 and WFS03) and chemically bonded (WFS02, WFS04, and WFS05) showed a result variation, as indicated in Table 3. The chemically bonded WFS's exhibited a comparatively high $\mathrm{pH}$ values of 9.89, 9.52, and 9.34, compared to the clay-bonded sands, which exhibited comparatively low $\mathrm{pH}$ values of 8.88 and 8.78 , respectively. The slightly lower $\mathrm{pH}$ values of clay bonded (WFS01 and WFS03) might be because of acidic cations (binder) presence and type of metal been cast. The $\mathrm{pH}$ results disclose that both types of WFS's used in this study possess a specified $\mathrm{pH}$ level of strong alkalinity and pose no threat to the environment.

TABLE 4: CHEMICAL COMPOSITIONS (MASS \%) OF ALL THE WFS SAMPLES AS DETERMINED BY XRF

\begin{tabular}{clllll}
\hline \hline Compositions & \multirow{5}{c}{ Value (\%) } \\
& WFS01 & WFS02 & WFS03 & WFS04 & WFS05 \\
\hline \hline $\mathrm{SiO}_{2}$ & 82.68 & 88.82 & 73.00 & 89.32 & 68.93 \\
$\mathrm{Al}_{2} \mathrm{O}_{3}$ & 8.10 & 3.22 & 11.90 & 2.01 & 6.23 \\
$\mathrm{Fe}_{2} \mathrm{O}_{3}$ & 3.54 & 2.82 & 6.33 & 3.26 & 8.31 \\
$\mathrm{CaO}$ & - & - & 1.92 & - & - \\
$\mathrm{MgO}$ & 1.48 & - & 2.16 & - & - \\
$\mathrm{SO}_{3}$ & - & - & 1.26 & - & - \\
$\mathrm{Na}_{2} \mathrm{O}$ & - & 1.03 & 1.36 & 2.87 & - \\
$\mathrm{K}_{2} \mathrm{O}$ & 1.15 & 2.53 & - & - & 3.18 \\
$\mathrm{TiO}_{2}$ & - & - & - & - & - \\
$\mathrm{Mn}_{2} \mathrm{O}_{3}$ & - & - & - & - & - \\
$\mathrm{SrO}_{\mathrm{CrO}}$ & - & - & - & - & - \\
$\mathrm{Cr}_{2} \mathrm{O}_{3}$ & - & - & - & - & 3.30 \\
$\mathrm{LOI}$ & 4.8 & 3.39 & 15.58 & 4.35 & 3.88 \\
\hline \hline
\end{tabular}

\section{CONCLUSION}

The physical and chemical results of the five WFS's analysed indicated acceptable variations in chemically bonded moulding sand but proved unacceptable in the case of the green sand. The unacceptable aspect for green sand was because of their clay contents, poor grading (cannot be blended with other sands), contain a very fine and silt particle, which can cause bleeding, and segregation. There is a correlation between the properties between chemically bonded samples and research done by previous researchers on the gradation, moisture content, fineness modulus, and specific gravity. The chemical characteristics of the chemically bonded sands also correlate with the results from previous researchers on XRF and $\mathrm{pH}$.

\section{ACKNOWLEDGMENT}

The authors would like to acknowledge the funding support from University of Johannesburg and support extended by Foundry Industries based in Gauteng (Auto Industrial Isando Foundry, Guestro Casting Machining, Forbes Bros Foundry, Johannesburg Foundry - Sinvac, and Thomas Foundry) with regard to provided WFS samples for completion of this research.

\section{REFERENCES}

[1] C.L. Tony, C. Jean-Chuan, "Sustainable concrete technology challenge

[2] John Hart and opportunity," National Taiwan University, Taiwan ROC, 2010.

[3] John Hart and Associates, "Ancient cementitious materials. Waste isolation pilot plant," Carlsbad, New Mexico, 2000.

[4] D.A.R. Dolage, M.G.S. Dias, C.T. Ariyawansa, "Offshore sand as a fine aggregate for concrete production," British Journal of Applied Science and Technology., vol. 3, no. 4, pp. 813-825, 2013.

[5] National Environmental Management: Waste Act, 2008 (Act 59 of 2008) National Environmental Management: Waste Amendment Act, 2014 (Act 26 0f 2014)

[6] R. Siddique, S. Gurpreet, "Utilization of waste foundry sand (WFS) in concrete manufacturing," Resources, Conservation and Recycling., vol. 55, no. 11, pp. 885-892, 2011.

[7] E.A. Dayton, S.D. Whitacre, R.S. Dungan, N.T. Basta, "Characterization of physical and chemical properties of spent foundry sands pertinent to beneficial use in manufactured soils," Plant Soil., vol. 329 , no. 27, pp. 27-33, 2010

[8] P.R. Carey, G. Sturtz, "Sand binder systems part IV urethane binders," Foundry Management and Technology., vol. 123, no. 25-9, 1995.

[9] A.N. Deng, P.J. Tikalsky, "Metallic characterization of foundry byproducts per waste streams and leaching protocols," Journal. of Environ. Engr., vol. 136, no. 6, pp. 586-96, 2006.

[10] M. Etxeberria, C. Pacheco, J.M. Meneses, I. Berridi, "Properties of concrete using metallurgical industrial by-products as aggregates," Constr. Build Mater., vol. 24, no. 9, pp. 1594-1600, (2010).

[11] American Foundrymen's Society, "Alternative utilization of foundry waste sand," Final Report (Phase I) prepared by American Foundrymen's Society Inc. for Illinois Department of Commerce and Community Affairs, Des Plaines, Illinois, 1991.

[12] C.K. Johnson, "Phenols in foundry waste sand modern casting," American Foundrymen's Society, 1981.

[13] MNR, (1992). On the Mineral aggregate conservation Reuse and recycling," Report prepared by John Emery Geotechnical Engineering Limited for Aggregate and Petroleum Resources Section, Ontario Ministry of Natural Resources, Queen's Printer for Ontario.

[14] ASTM E2418-06, "Standard Guide for Readily Observable Mold and Conditions Conducive to Mold in Commercial Buildings," Baseline 
Survey Process (Withdrawn 2015), ASTM International, West Conshohocken, PA, 2006.

[15] A.M. Neville, "Properties of Concrete," Fifth Edition: Pearson Education Limited, England, 2011.

[16] SANS 201:2008, Sieve analysis, fines content and dust content of aggregates.

[17] TMH1-Method A6, the determination of the grain size distribution in soils by means of a hydrometer.

[18] SANS 3001-AG23:2014, Civil engineering test methods Part AG23: Particle and relative densities of aggregates.

[19] SANS 3001-GR20, Civil engineering test methods Part GR20: Determination of the moisture content by oven-drying.

[20] SANS 5845:2006, Bulk densities and voids content of aggregates.

[21] G. Grieve, "Aggregates for concrete" G. Owen, (ed.). Fulton's concrete technology. 9th Edition. Midrand, South Africa: Cement and Concrete Institute, 2009a.

[22] D.I. Cole, J.H.A Viljoen, Building sand potential of the Greater Cape Town area. Bulletin, Council for Geoscience, Number 129, (2001) 31p.

[23] SABS 11: $1990-3$ rd. Revision, $\mathrm{pH}\left(\right.$ at $\left.25^{\circ} \mathrm{C}\right)-\mathrm{Lab}$.

[24] American Foundrymen's Society, Report on Alternate Utilization of Foundry Waste Sand, " Phase I, Report No: IDCCA-1, AFS, Des Plaines, Illinois, pp 97, 1991.

[25] ASTM D2487 - 06, Standard Practice for Classification of Soils for Engineering Purposes (Unified Soil Classification System.

[26] J.R. Kleven, T.B Edil, C.H. Benson, "Evaluation of excess foundry system sands for use as sub-base material," Transportation Research Record., vol. 1714, pp. 40-48, 2000.

[27] T.R. Naik, S.S Singh, "Performance and leaching assessment of flowable slurry," J Environ Eng., vol. 127, no. 4, pp. 359, 2001.

[28] SANS 1083: 2017, Aggregates from natural sources - Aggregates for concrete.

[29] M. Alexander, S, Mindess, "Aggregates in concrete" Taylor and Francis, Specification for Aggregates for natural source for concrete, 2005.

[30] T. Abichou, T.B Edil, C.H. Benson, H. Bahia, "Beneficial use of foundry by-products in highway construction" Geotechnical Engineering for transportation projects, Geotechnical Special Publications., ASCE, Reston, vol. 126, pp 715-22, 2004.

[31] S.W. Mclntyre, K.B. Rundman, C.R. Bailhood, P. Rush, J. Sandell, B. Stillwell, "The Beneficiation and Reuse of Foundry Sand Residuals," A Preliminary Report, Michigan Technological University, Houghton, Michigan, pp 36, October, 1991.

[32] Eric. S. Winkler, A. Alexander. Bol'shakov, Characterization of Foundry Sand Waste: Chelsea Center for Recycling and Economic Development Technical Research Program, 2000.

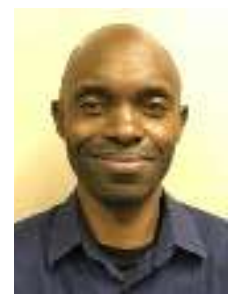

Patrick I. Iloh is finishing his master's research at Department of Civil Engineering Technology, Faculty of Engineering and the Built Environment, University of Johannesburg, South Africa. He qualified Bachelor of Civil Engineering from Institute of Management and Technology (IMT), Enugu State, Nigeria during 1998. Patrick's masters research work is on 'Effect of Waste Foundry Sand (WFS) on Concrete Properties' based on the selected foundries of Gauteng, South Africa. His masters research is supervised by Prof George Fanourakis, Department of Civil Engineering Technology, and co-supervised by Mr Aurobindo Ogra, Department of Town and Regional Planning, Faculty of Engineering and the Built Environment, University of Johannesburg.

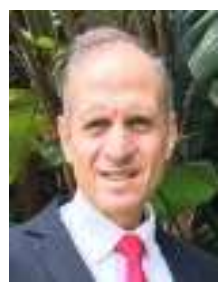

Professor George Fanourakis joined the Department of Civil Engineering Technology at the (now) University of Johannesburg over 23 years ago, after leaving the employ of Jones and Wagener (Pty) Consulting Engineers. He holds the degrees of $\mathrm{MSc}(\mathrm{Eng})$ and DTech(Eng). He is a Chartered Civil Engineer and Fellow of the Institution of Civil Engineers (UK). He is a Fellow of the South African Institution of Civil Engineering, Honorary Fellow (and Past-President) of the Institute of Professional Engineering Technologists (IPET) and Member of the Soil Science Society of Southern Africa. He received the 2006 Best Journal Paper Award from SAICE.

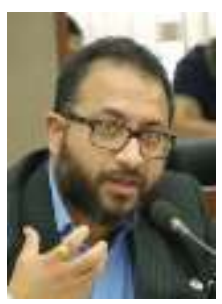

Aurobindo Ogra is a Professional Planner (SACPLAN) and lectures at Department of Town and Regional Planning, Faculty of Engineering and the Built Environment, University of Johannesburg. $\mathrm{He}$ is qualified in BTech (Construction Technology), Masters (Urban \& Regional Planning), Masters (Business Economics) and finishing Doctoral Research (Engineering Management). $\mathrm{He}$ has 16 years of international professional experience in areas of urban sector with specialisation in urban planning, infrastructure development and urban management. His current research interest areas spans across: urban infrastructure planning and development, smart cities, waste management, among other areas of built environment sector. 